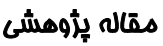

\section{افسردكى در مردان مبتلا به نارسايى سيستوليك قلبى و فاكتور هاى مرتبط با آن}

\author{
شراره ضيغمى محملى ا" ، ماند/نا شهبريان "، فرزاد فهيدى "، ابراهيم فلاح"r
}

$$
\begin{aligned}
& \text { 'مربى گروه يرستارى دانشكده يرستارى و مامايى دانشخاه آزاد اسلامى واحد كرج }
\end{aligned}
$$

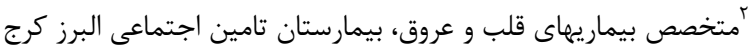

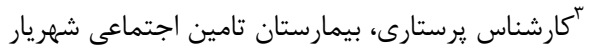

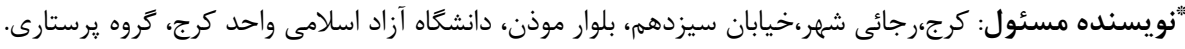
يست الكترونيك: zeighami@kiau.ac.ir

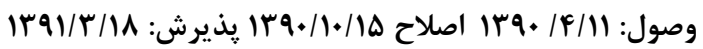

جكيده

زمينه و هدف: افسردكى با /فزايش وخامت بيمارى، طول مدت بسترى و مرك و مير بيماران مبتلا به نارسايى قلبى /رتباط دارد. هدف /ز

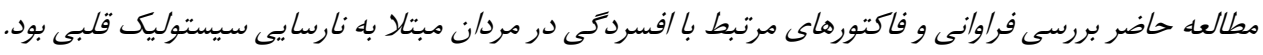

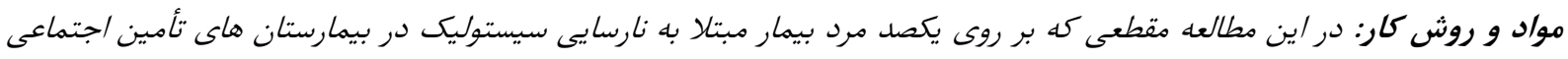

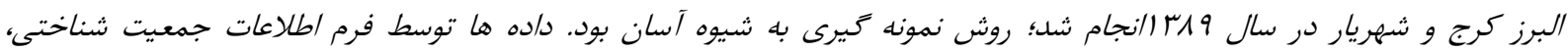

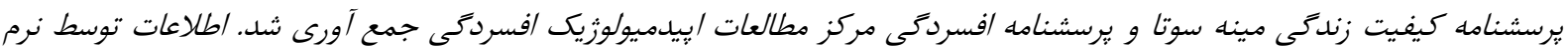

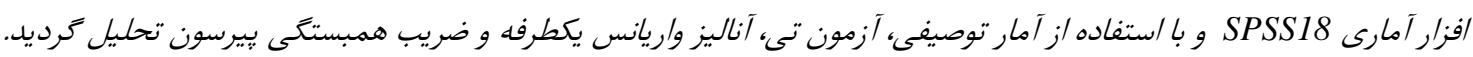

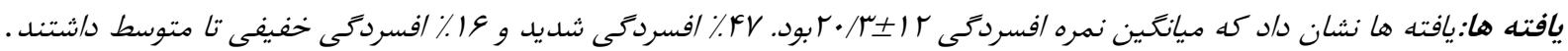

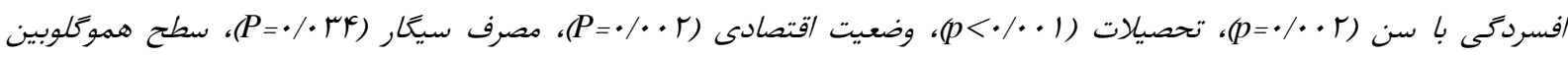

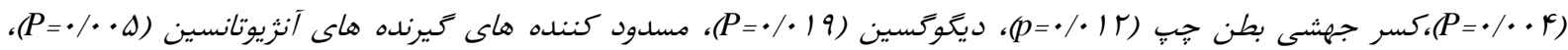

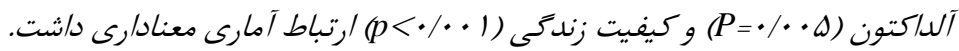

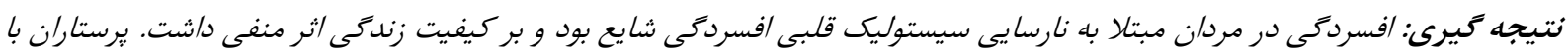

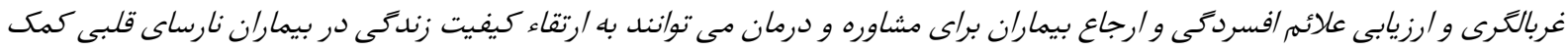

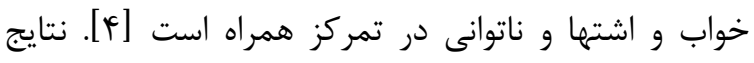

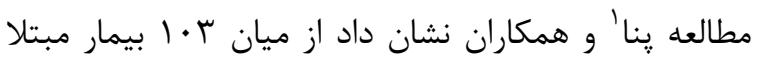

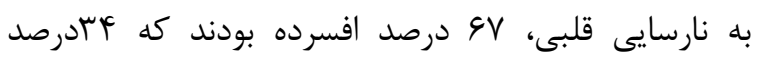

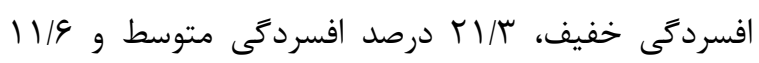
درصد افسردگى شديد داشتند [ه].

1 - Pena
نارسايى سيستوليك قلبى، سندرمى بالينى است كه به دليل

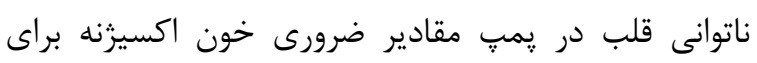

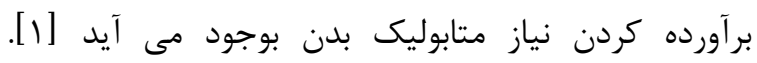
افزايش حجم خون، يرفيوزن ناكافى و كاهش تحمل فعاليت

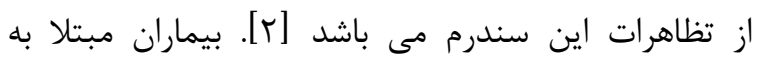
نارسايى قلبى در معرض ابتلا به افسردگى قرار دارند [ب] سئ.

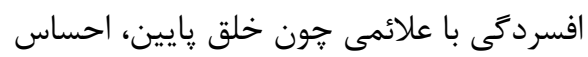


جنس يك فاكتور مرتبط با افسردگى شناخته شده است. در

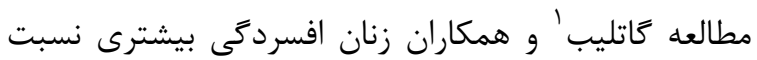
به مردان داشتند [rT]. در حاليكه در مطالعه ماكاباسكو

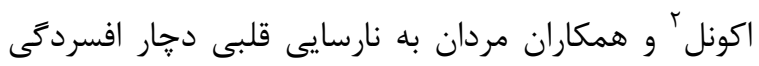

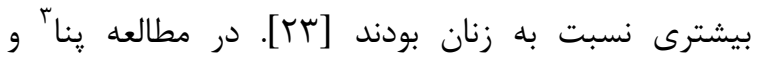

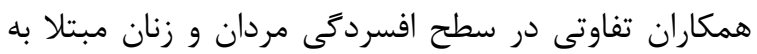
نارسايى قلب مشاهده نشد [V]]. يافته هاى ضد و نقيضى در رابطه با افسردكى در مردان وجود دارد. با توجه به اهميت

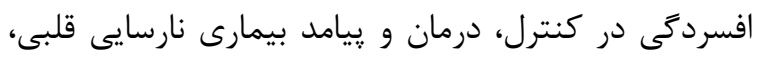
اين مطالعه با هدف تعيين فراوانى افسردگى در مردان مبتلا به نارسايى سيستوليك قلبى و فاكتورهاى مرتبط با آن، در دو بيمارستان تامين اجتماعى البرز كرج و بيمارستان تامين

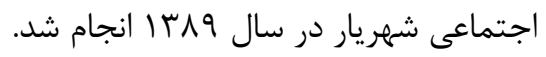

روش كار

مطالعه حاضر از نوع توصيفى و مقطعى بود كه در آن افسردگى و فاكتورهاى مرتبط با آن در يكصد مرد مبتلا به نارسايى سيستوليك قلبى مورد بررسى قرار گرفت. جامعه

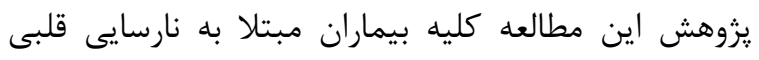
بسترى در بخش داخلى بيمارستان تامين اجتماعى البرز كرج و بيمارستان تامين اجتماعى شهريار طى تيرماه تا

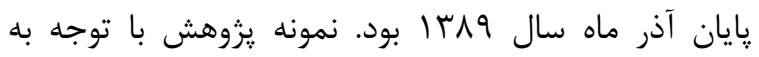

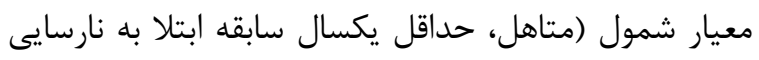

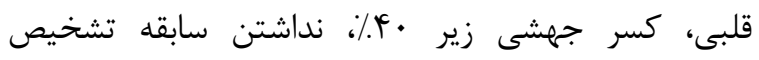

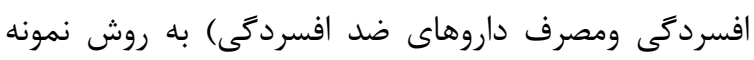
كيرى آسان از جامعه يزوهش انتخاب شدند. نحوه اجراى

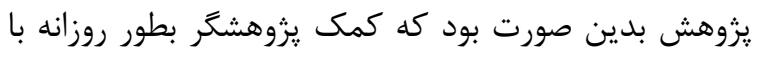

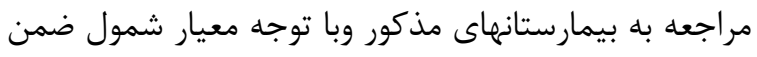
توضيح هدف كلى يزوهش، ابزار يروهش را به روش مصاحبه

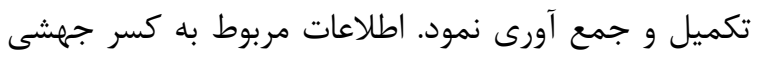

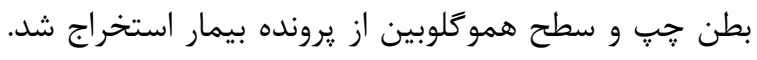

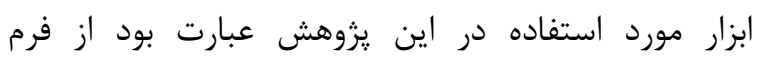
مشخصات دموگرافيك (سن، وضعيت تاهل، تحصيلات،

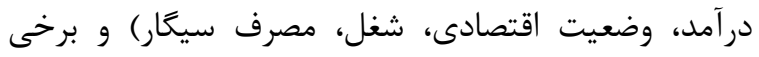
اطلاعات مربوط به بيمارى (طول مدت ابتلا به بيمارى، نوع بيمارى مزمن همراه با نارسايى قلبى، نوع داروهاى مصرفى، بيماري،

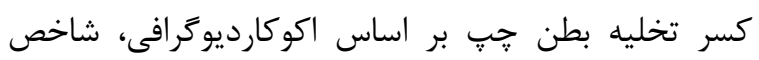

1- Gottlieb

2- Macabasco-O'Connell
رزيم غذايى خاص و محدود از سديم، از دست دادن طعم دليذير غذا و اجبار براى پيروى از آن، احساس ايزوله بودن

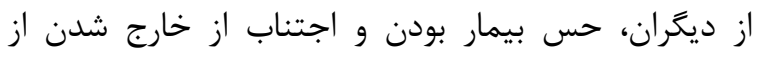

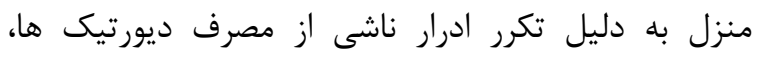
زنيكوماستى و اختلال در تصوير ذهنى از خود بند بدنبال

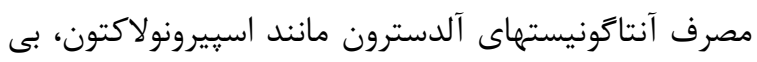
خوابى، خستكى و اختلال نعوظ ناشى از عوارض داروهاى

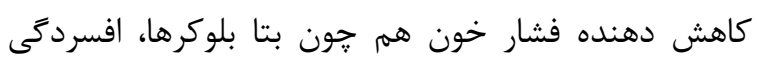

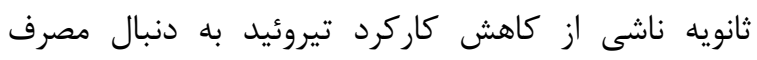

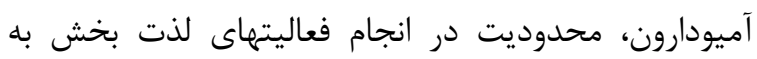

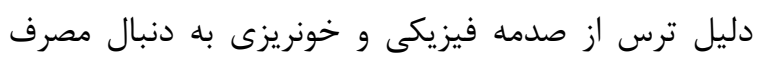

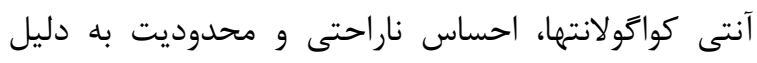

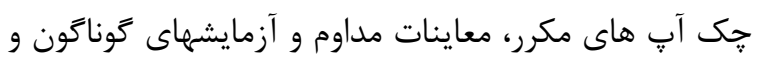
هزينه هاى بالاى درمان زمينه بروز افسردگى در بيماران

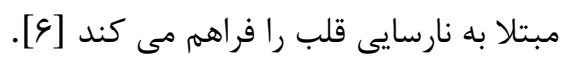
مطالعات مختلف بيانكر آن است كه عواملى هونى هن

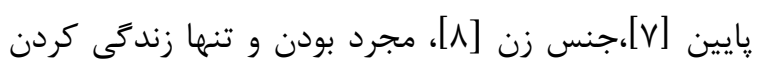

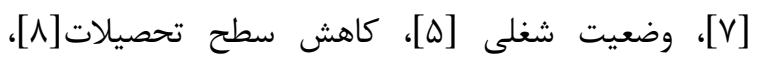

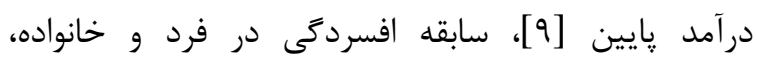

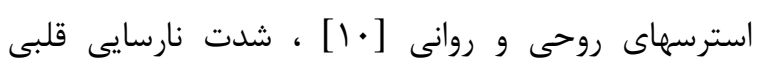

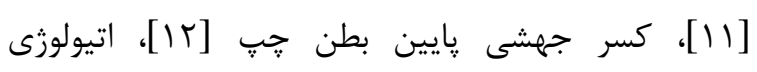

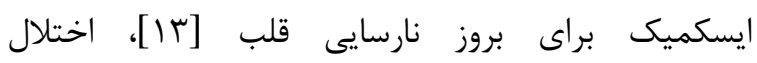
عملكردجنسى [1 [ [ ]]، كاهش عملكرد جسمى و نارضايتى از

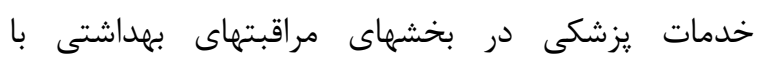

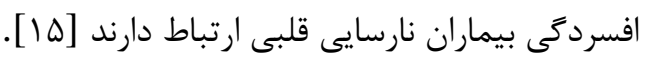

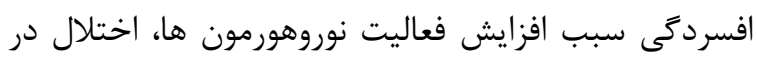

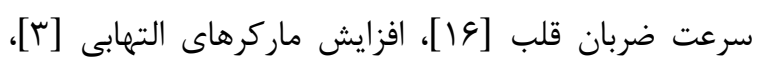
افزايش انعقاد يذيرى شده [IV] و با كاهش متابعت از مان رزيم

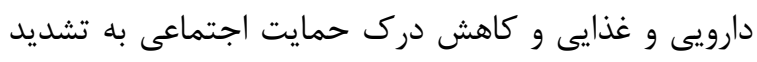
علائم نارسايى قلبى كمك مى كند [19

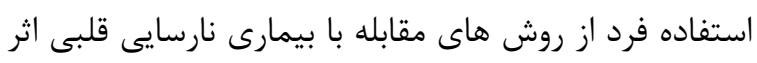
منفى گذاشته و سبب مى گردد كه بيمار بيشتر از شيوه هاى اجتنابى، به جاى روشهاى فعال از عهده برايى استفاده

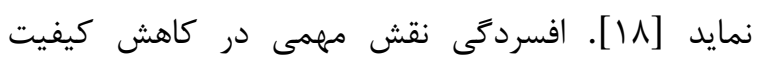
زندگى [19] و افزايش هزينه هاى درمانى بيمارداشته [ـ [ب]

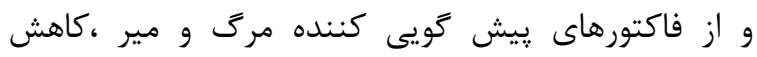
يروكنوز [YI] و افزايش موارد بسترى مجدد در بيث بيماران

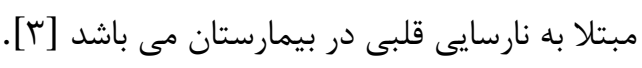


علائم روانى مانند افسردىى و اضطراب، روابط اجتماعى،

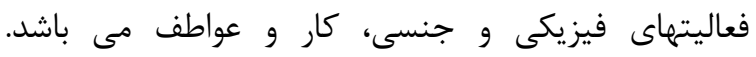

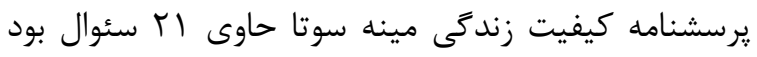

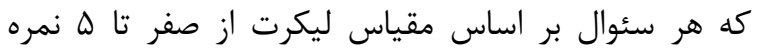
كذارى شده بود، عدد صفر نشاندهنده بهترين حالت و و عدد ه نشاندهنده بدترين حالت بود. دامنه نمرات بين • تاهـ •

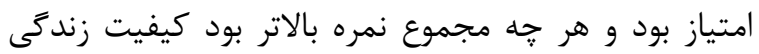

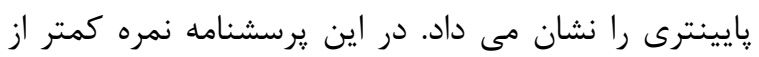

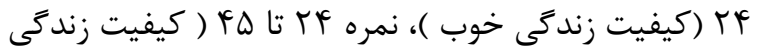

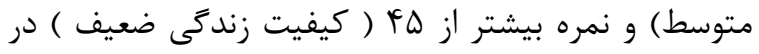

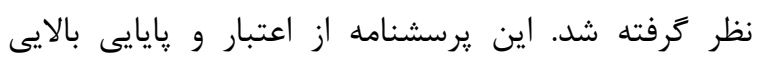

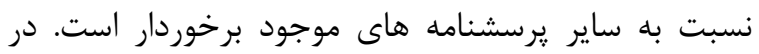

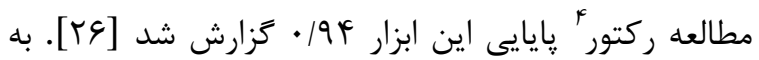

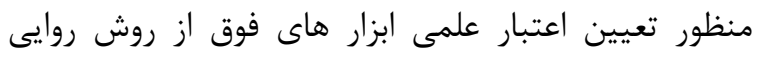

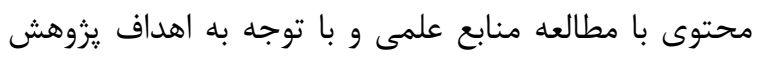
استفاده شد. در مطالعه فعلى به منظور تعيين ضريب بايائي

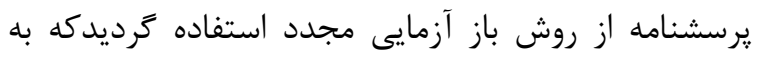

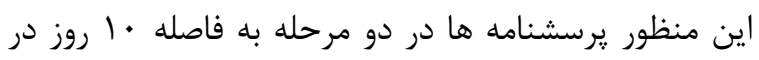

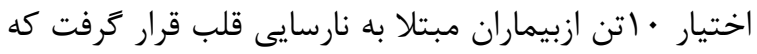

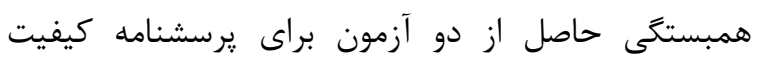

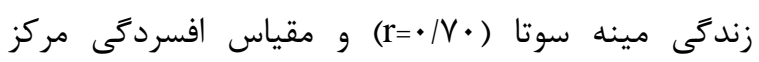

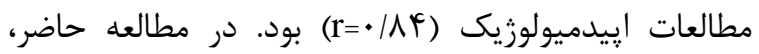
منظور ازكشيدن سيخار مصرف حداقل يك نخ سيخار در روز

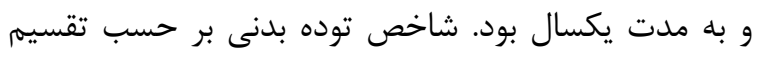

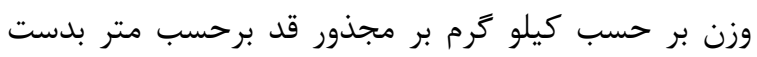

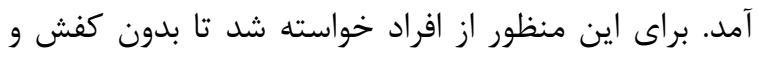

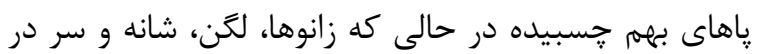

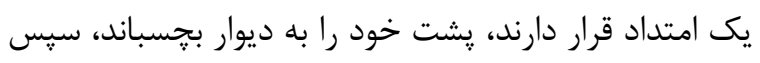

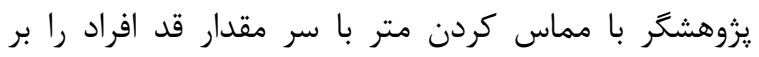

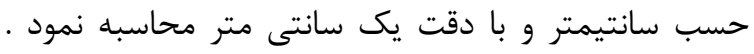

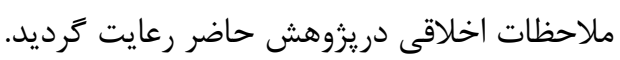

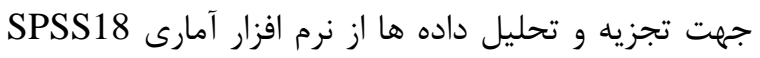
استفاده شد. داده ها توسط جداول توزيع فراوانى، ميانخين و

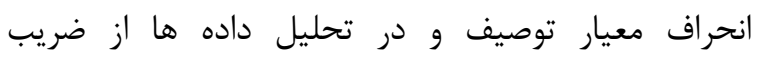

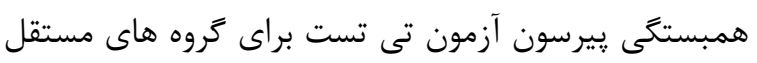

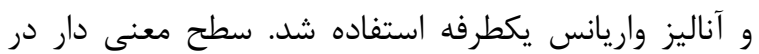
اين يزوهش ه • • • در نظر كرفته شد.
توده بدنى، بررسى سطح هموكلوبين سرم)، يرسشنامه

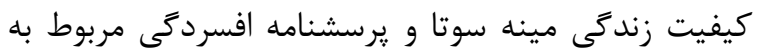
مركز مطالعات إيدميولوزيك افسردحى. الف:يرسشنامه

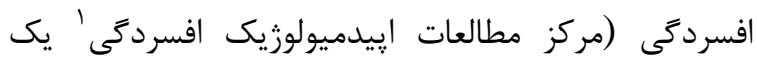
يرسشنامه بين المللى روا و وايا براى سنجش افسردگى إنى است كه از ادغام جندين يرسشنامه سنجش افسردگى (برى

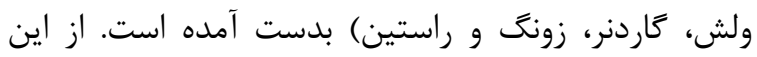

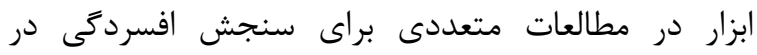

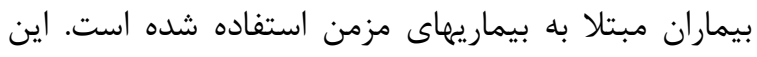

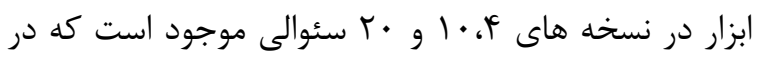

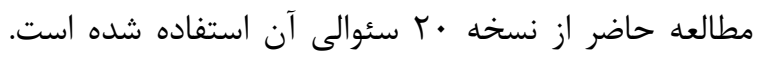

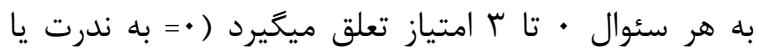

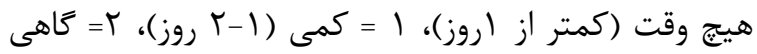

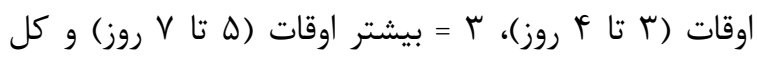

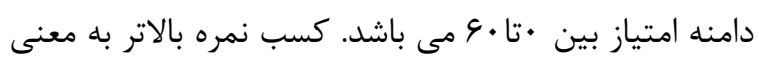
ميزان افسردىى بيشتر مى باشد. براساس اين ابزار نمره

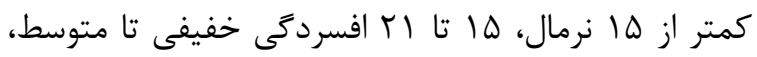

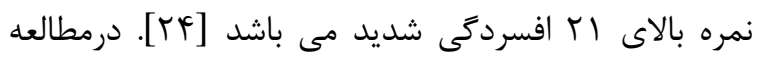

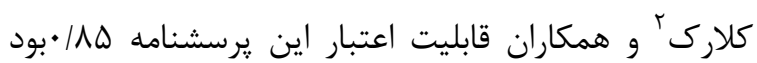

ب: برسشنامه كيفيت زندگى مينه سوتاًّ به منظور كسب اطلاعاتى در مورد كيفيت زندگى بيماران مبتلا به نارسايى مئي

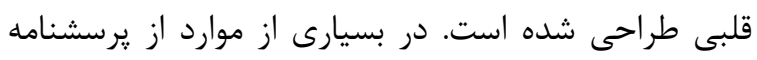

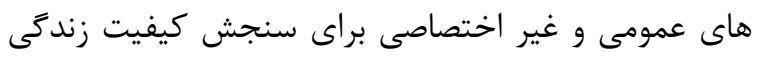

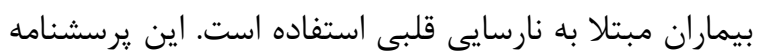

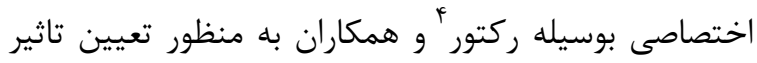

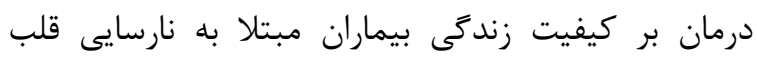

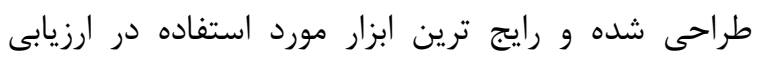
كيفيت زندگى اين بيماران در مطالعات تحقيقى است. اين اين

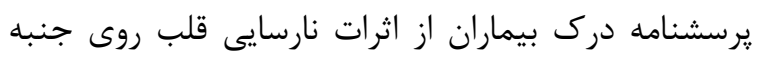

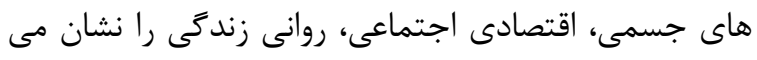
دهد. سئوالات اين يرسشنامه در رابطه با علائم بيمارى زئمى مانند تنكى نفس، خستخى، ادم محيطى، اختلال در خواب و

1 - Center for Epidemiologic Studies Depression Scale

2 - Clark

3- Minnesota Living with Heart Failure questionnaire

4 -Rector 
مبدل آنزيوتانسين، ه درصد تحت درمان با كلسيم بلوكر،

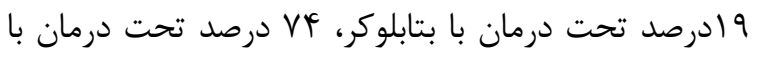
نيترات، هآدرصد تحت درمان با بلوك كننده هاى

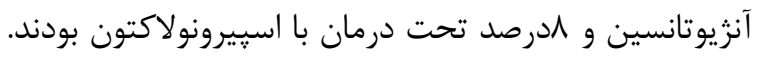

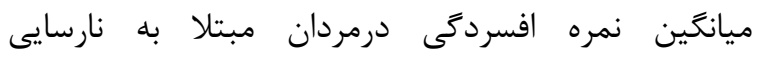

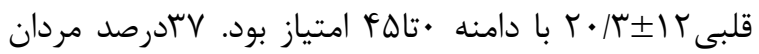

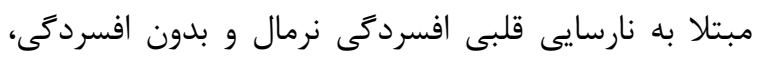

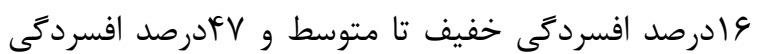
شديد داشتند.

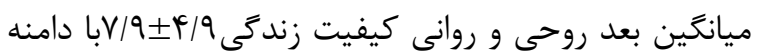

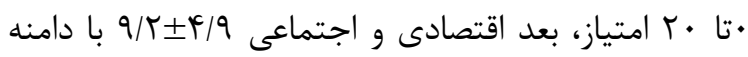

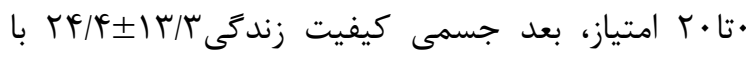

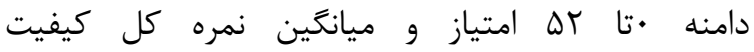

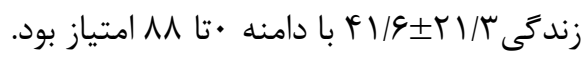

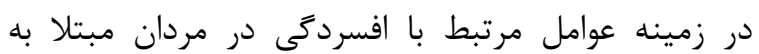
نارسايى سيستوليك قلبى، نتايج آزمون ضريب همبستئى دردي دردي
يافته ها

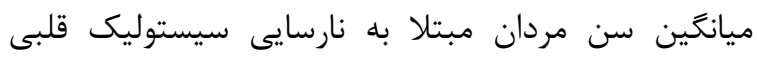

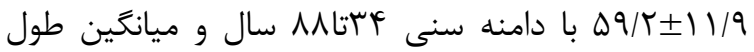
مدت ابتلا به نارسايى قلبى

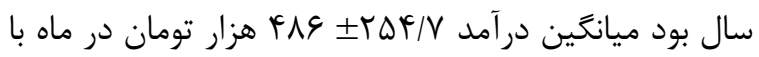
دامنه دويست هزارتومان تا دو ميليون جهارصد هزار تومان

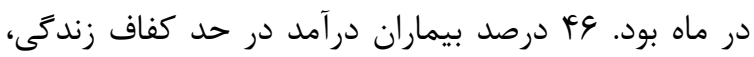

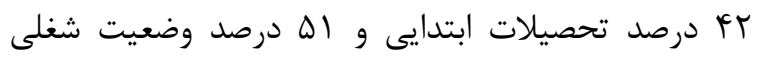

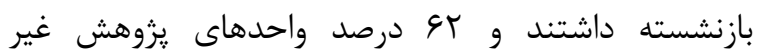

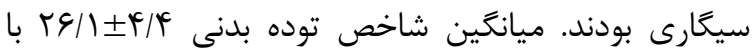

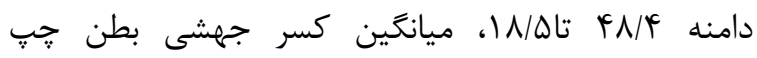

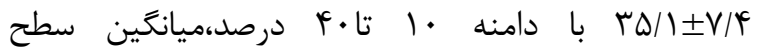

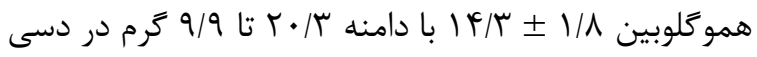

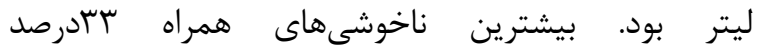

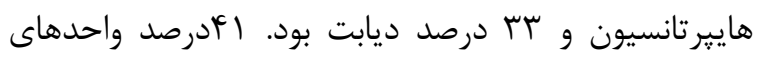
يزوهش تحت درمان با ديگو گسين، بسادرصد تحت درمان با ديورتيك، و ب درصد تحت درمان با مهار كننده آنزيم

\begin{tabular}{|c|c|c|}
\hline $\mathrm{r}=\cdot / \mu / r$ & $\mathrm{p}=\cdot / \cdot \cdot r$ & 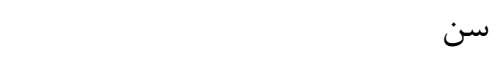 \\
\hline$r=-\cdot / l \Delta r$ & $\mathrm{p}=\cdot / \mathrm{rV}$ & 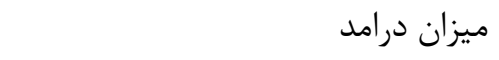 \\
\hline $\mathrm{r}=\cdot \cdot \cdot \cdot \mathrm{gr}$ & $\mathrm{p}=\cdot\left|\Delta \mu^{\prime}\right|$ & طول مدت ابتلا \\
\hline $\mathrm{r}=\cdot 1199$ & $\mathrm{p}=\cdot / r q 4$ & تعداد نخ سيكارمصرفى \\
\hline $\mathrm{r}=-\cdot / r \wedge \Delta$ & $\mathrm{p}=\cdot / \cdot \cdot \mathrm{F}$ & همو كلوبين \\
\hline $\mathrm{r}=-\cdot / r \Delta \cdot$ & $\mathrm{p}=\cdot / \cdot 1 \mathrm{r}$ & كسرجهشى بطن جي \\
\hline $\mathrm{r}=-\cdot / l f F$ & $\mathrm{p}=\cdot / / \Delta F$ & شاخص توده بدنى \\
\hline $\mathrm{r}=\cdot / \vee q \wedge$ & $\mathrm{p}<\cdot / \cdot \cdot 1$ & بعدروحى و روانى كيفيت زندگى \\
\hline $\mathrm{r}=\cdot \mid \varepsilon \wedge \mu$ & $\mathrm{p}<\cdot / \cdot \cdot 1$ & بعداقتصادى و اجتماعى كيفيت زندكى \\
\hline $\mathrm{r}=\cdot / \mathrm{V} \uparrow \Lambda$ & $\mathrm{p}<\cdot / \cdot \cdot 1$ & بعد جسمى كيفيت زندكى \\
\hline $\mathrm{r}=\cdot / \uparrow q f$ & $\mathrm{p}<\cdot / \cdot \cdot 1$ & كيفيت زندكى \\
\hline
\end{tabular}




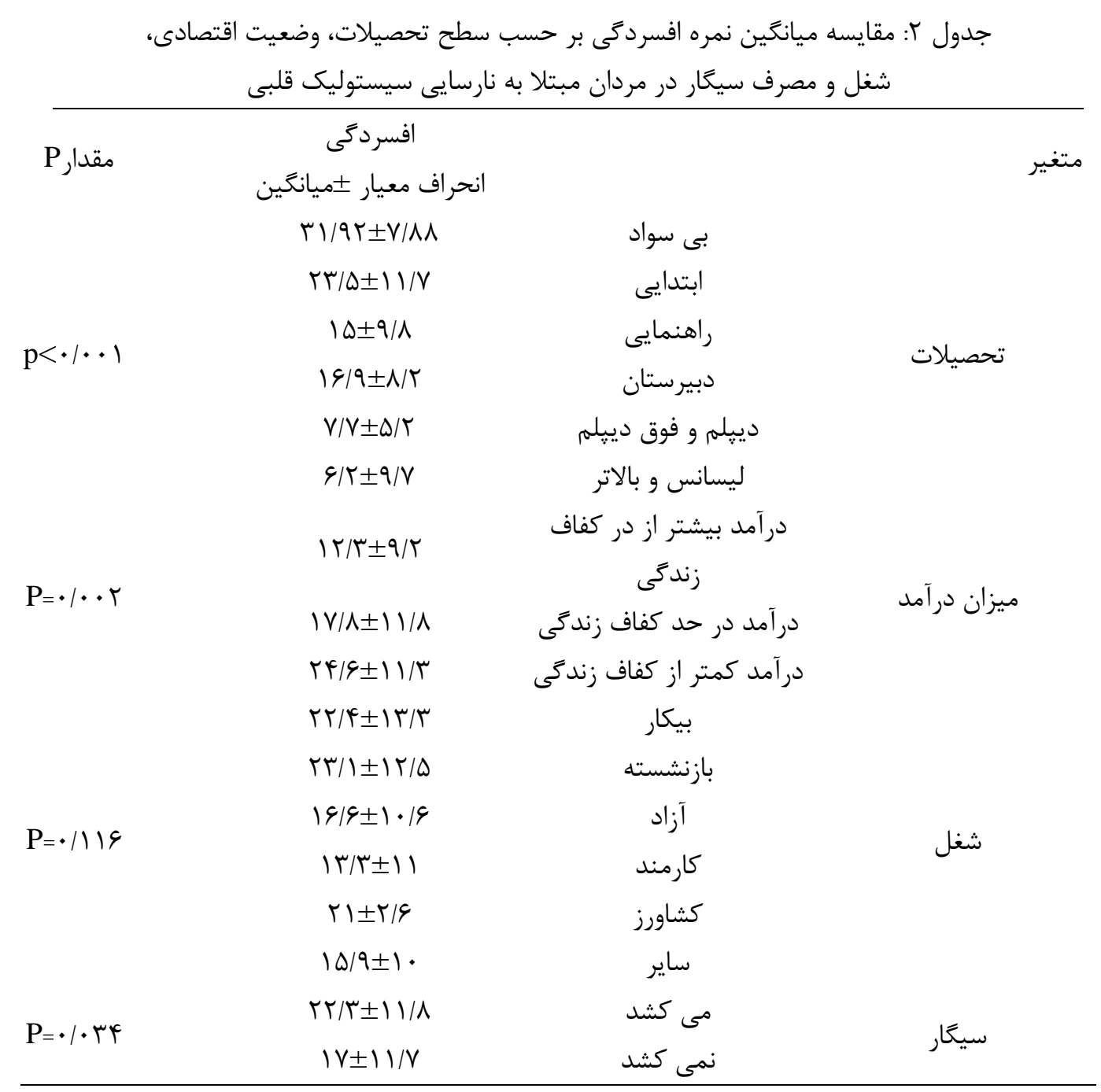

جدول Y تفاوت آمارى معنادارى در ميانگين نمره افسردىى بر حسب تحصيلات، وضعيت اقتصادى، مصرف سيكار نشان

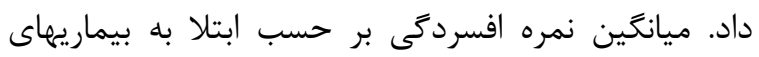

مزمن همراه اختلاف آمارى معنادار نداشت. (جدول بَ)

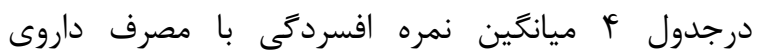

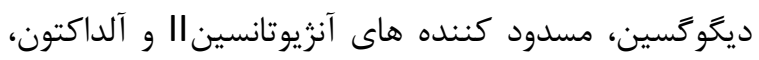

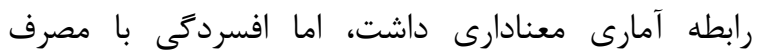

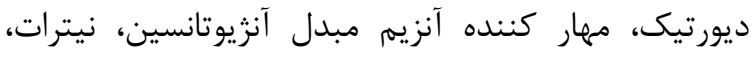

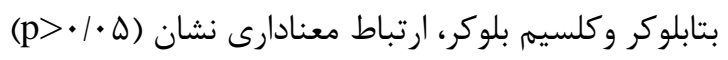

ييرسون همبستگى مستقيم و معنا دارى بين افسردگى با

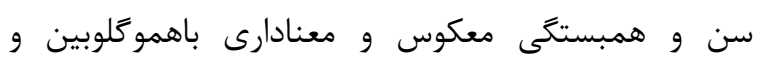
كسرجهشى بطن קֶٍ نشان داد. همجنين بين افسردكى و

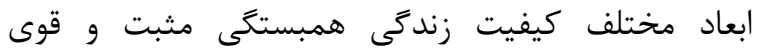

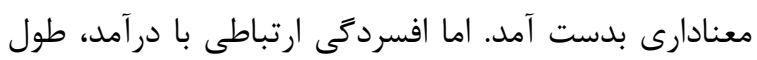

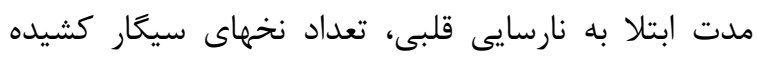
شده در طول روز و شاخص توده بدنى در مردان مبتلا به

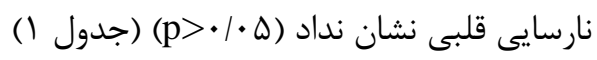




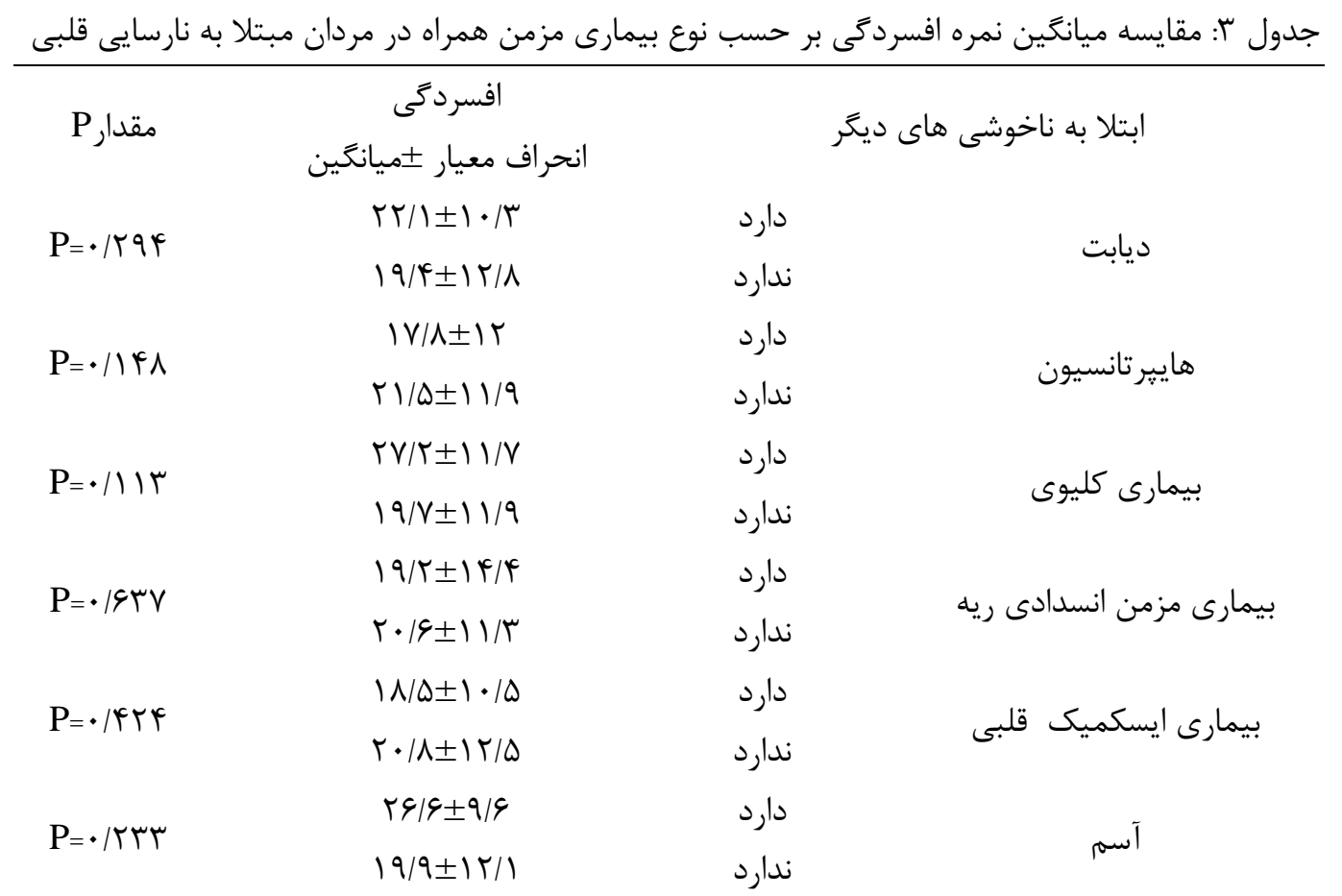

جدول f: مقايسه ميانگين نمره افسردگى بر حسب مصرف برخى داروها در مردان مبتلا به نارسايى سيستوليك قلبى

\begin{tabular}{|c|c|c|c|}
\hline مقدار P P & انحراف معيار ذئيانغين & & نوع داروهاى مصرفى \\
\hline $\mathrm{P}=\cdot 1 \cdot 19$ & $\begin{array}{l}r \Psi / 9 \pm 1 \mid / \Lambda \\
|V / q \pm| \mid / V\end{array}$ & نمى گَيرد & ديكو گسين \\
\hline $\mathrm{P}=\cdot / \Delta T \Delta$ & $\begin{array}{l}19 / 1 \pm 1 r / r \\
r \cdot / N \pm 1 r\end{array}$ & نمى گَيرد & مهار كننده آنزيم مبدل آنزيوتانسين \\
\hline $\mathrm{P}=\cdot / \cdots \Delta$ & $\begin{array}{l}r \Psi / q \pm|| / l \\
|V / \Lambda \pm| \mid / \Lambda\end{array}$ & نمى كير & مسدود كننده هاى آنزيوتانسين \\
\hline $\mathrm{P}=\cdot / \cdot \bullet$ & $\begin{array}{l}r \mid / g \pm V / r \\
19 / r \pm 1 \mid / 9\end{array}$ & نمى گَيرد & آلداكتون \\
\hline $\mathrm{P}=\cdot / \mathcal{A} T$ & $\begin{array}{l}r|/ \Delta \pm| r / 1 \\
19 / \Delta \pm 1 \mid / r\end{array}$ & نمى گيرد & ديورتيك \\
\hline $\mathrm{P}=\cdot \mid r T I$ & $\begin{array}{l}|Q / F \pm| r / r \\
r Y / \Lambda \pm \mid I / F\end{array}$ & نمى گَيرد & نيترات \\
\hline $\mathrm{P}=\cdot 19 \Delta \lambda$ & $\begin{array}{l}r|/ T \pm| r / q \\
r \cdot \pm I I / r\end{array}$ & نمى گَيرد & بتابلوكر \\
\hline $\mathrm{P}=\cdot / 9 \wedge \varepsilon$ & $\begin{array}{l}r \cdot \pm N / \Lambda \\
r \cdot \pm I r / r\end{array}$ & نمى گَيرد & كلسيم بلوكر \\
\hline
\end{tabular}


سالمندى، در افزايش فراوانى افسردىى در بيماران مسن نقش داشته باشد. در مطالعه حاضر بيمارانى كه سطح تحصيلات بالاترى

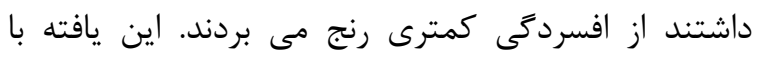

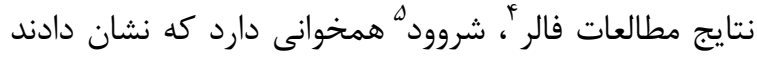
كاهش سطح تحصيلات با افزايش شدت افسردكى در

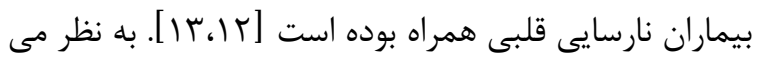
رسد احتمالاً سطح تحصيلات فرد بر ميزان آكَاهى فرد از

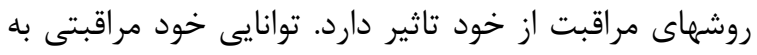

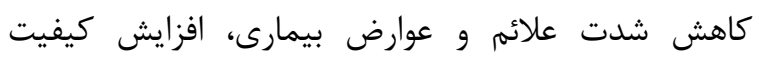
زندگى فرد و درنهايت بهبود خلق كمك مئ كلى كند.

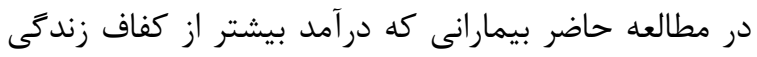
برخوردار بودند افسردىى كمترى داشتند. اين يافته با نتايج

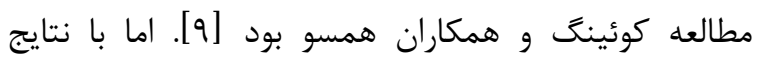

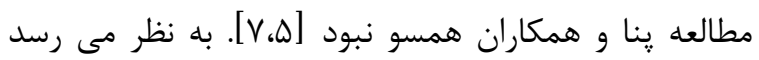

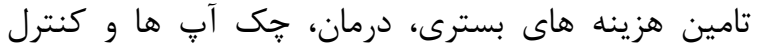

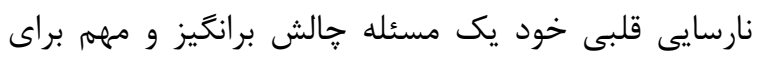

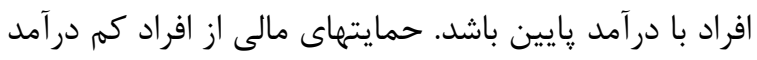

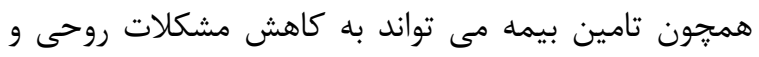
افسردى كمك نمايد.

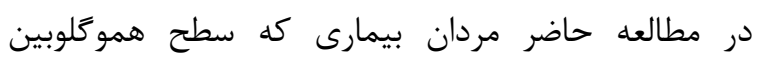

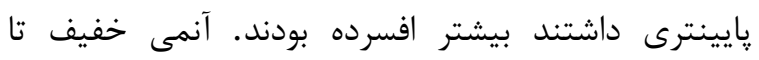

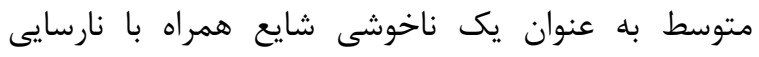

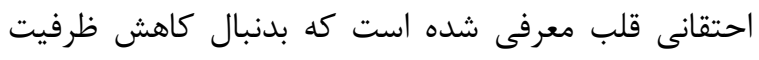

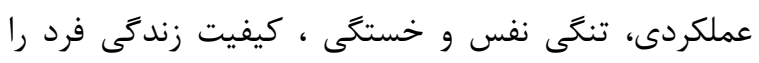

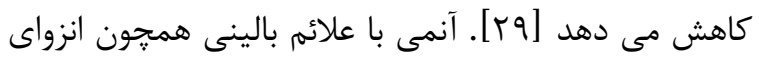

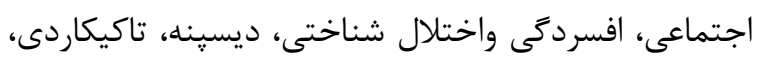

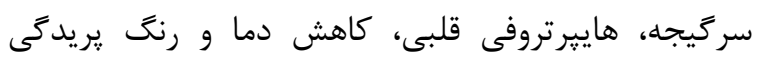

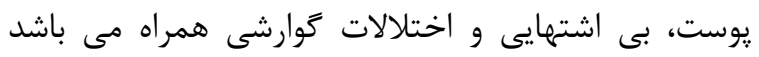

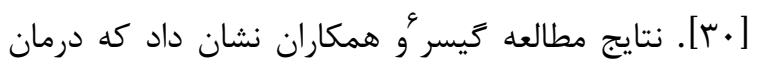

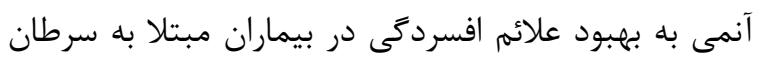

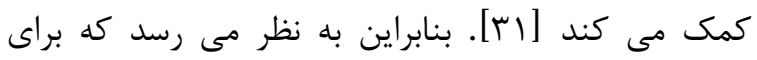

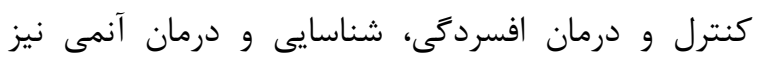
بايستى مد نظر قرار داده شود.

4 - Faller

5 - Sherwood

6- Geiser
مطالعه حاضر نشان داد كه FV درصد مردان مبتلا به نارسايى سيستوليك قلبى افسردگى شديد داشتند و وإن

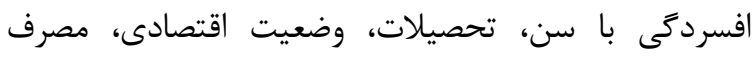

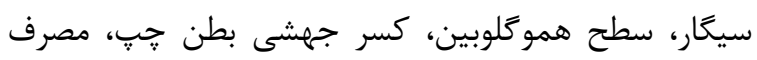

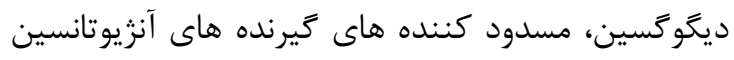

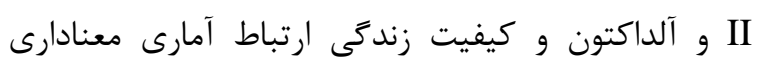
داشت. در مطالعه حاضر FV درصد از مردان مبتلا به نارسايى

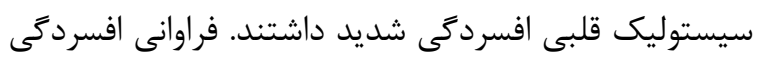

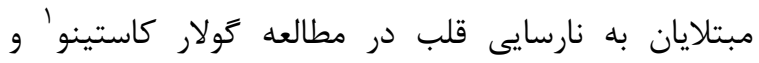

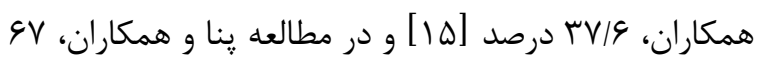

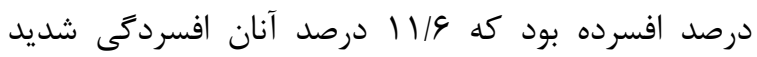

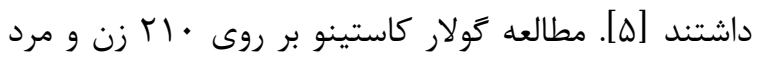
مبتلا به نارسايى قلبى درسنين بالاى له 1 سال و با استفاده

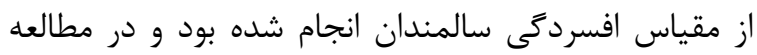

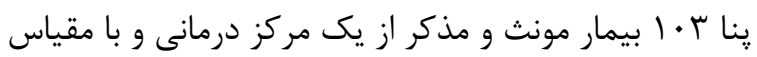

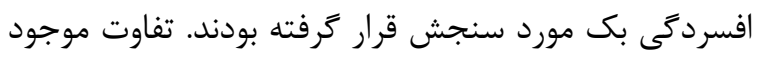

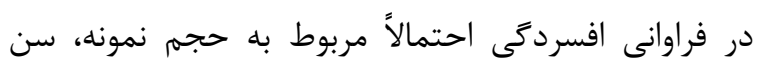

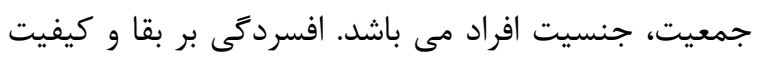

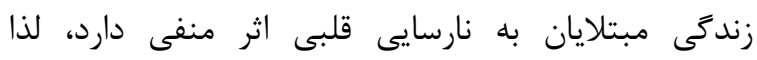

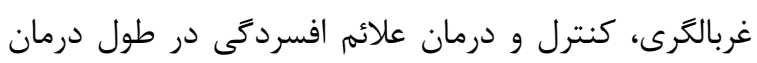
اين بيماران بايستى مورد توجه قرار كيرد.

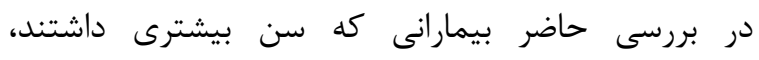

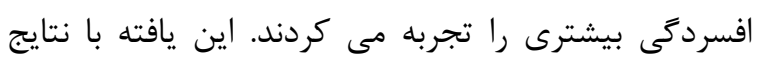

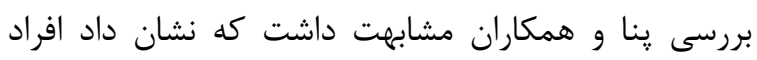

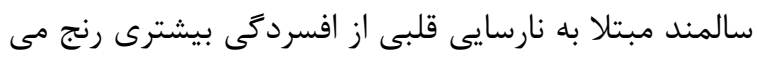

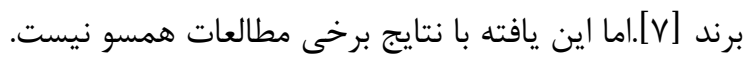

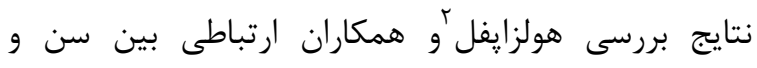

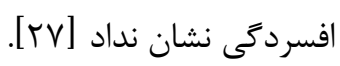

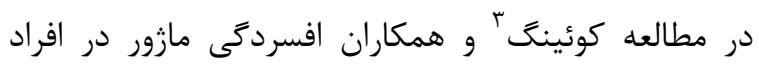

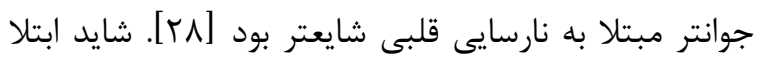

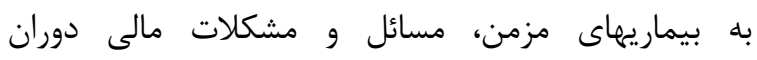
بازنشستكى و كاهش ميزان حمايت اجتماعى در دوران منان مانى دوران 
به نظر مى رسد خستخى، عدم تحمل فعاليت بدنى، مسائل و مشكلات مالى، اختلال در و اجتماعى ناشى از بيمارى و عوارض آن از جنبه هاى جسمى، اجتماعى و اقتصادى آنى

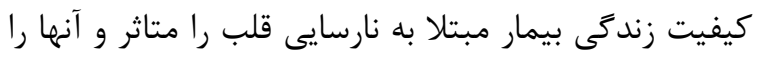
كاهش مى دهد اين امر ممكن است بر سلامت روحى و روانى فرد تاثير گذاشته و بيمار را با مشكلات روحى و روانى ميى همجون افسردگى مواجه سازد.

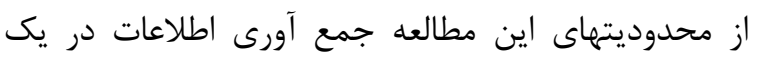
نقطه زمانى معين بود كه سير تغييرات خلقى در طول ابتلا به بيمارى و درمان شناسايى نشد، همجنين احتمال تشخيص

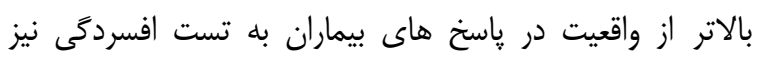
وجود داشت. حجم نمونه پايين از ساير محدوديت هاى يزوهش حاضر بود. لذا ييشنهاد مى گردد، مطالعات ديخرى

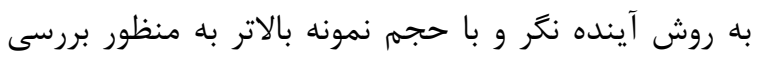
سير تغييرات خلقى در مبتلايان به نارسايى قلبى و تاثير آن بر مرگ و مير و طول مدت بسترى اين بيماران انجام گيرد.

\section{نتيجه كَيرى} افسردگى در مردان مبتلا به نارسايى سيستوليك قلبى افسردگى شايع بود و بر كيفيت زندگى اثر منفى داشت. اساس مراقبتهاى يرستارى كل نگر، توجه به نيازها و مشكلات روحى و روانى بيماران در كنار نيازها و مشكلات

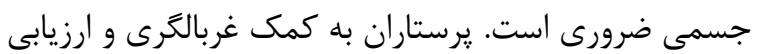
علائم افسردگى و ارجاع بيماران جهت مشاوره و درمان، مى

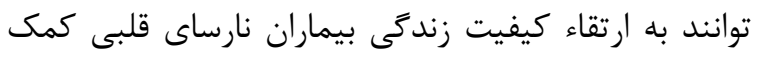
نمايند.

$$
\text { تشكر و قدردانى }
$$

مطالعه حاضر بخشى از نتايج طرح يزوهشى با كد

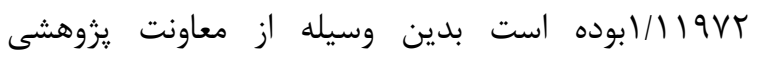
دانشعاه آزاد اسلامى واحد كرج جهت تصويب و حمايت مالى طرح يزوهشى تشكر و قدردانى مى گردد.

\section{References}

1. Zeighami Mohammadi Sh, Asgharzadeh Haghighi S, Nikbakht Nasrabadi A , The study of electrolyte abnormalities and renal dysfunction on elderly patients with systolic heart failure,Iranian Journal of Critical Care Nursing 2010; 3(4): 155-66 [Persian].

2. Nikravan Mofrad $M$, Text book of emergency nursing, Tehran, Noor-e-Danesh, 324-5 [Persian].
در مطالعه حاضر بيمارانى كه كسر جهشى بطن جِّ קإيينترى داشتند افسردىى بيشتر بود. اين يافته با نتايج يزروهش ينا، فالر، شروود همسو بود كه نشان داد بيمارانى بانى باني

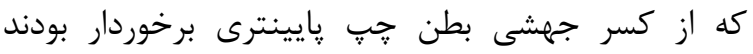

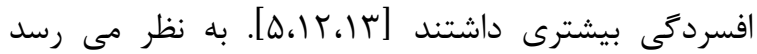
كاهش كسر جهشى با عدم تحمل فعاليت و خستخى و

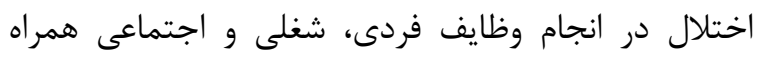
است كه در بروز اختلالات خلقى و افسردىى مى تواند موثر جنى باشد. در مطالعه حاضر بيماران مبتلا به نارسايى قلبى كه تحت

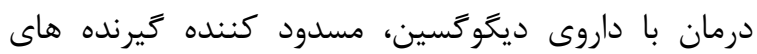

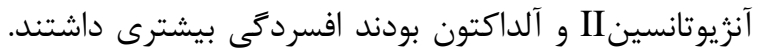

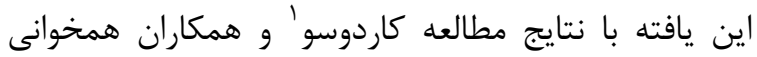

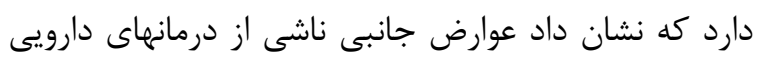

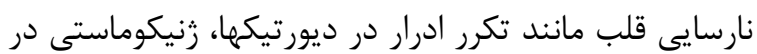

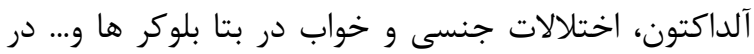

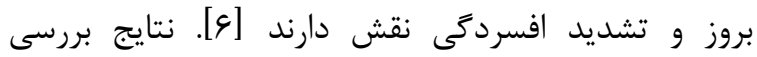

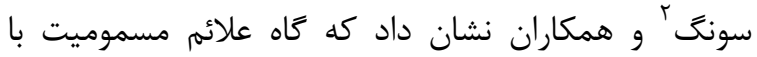

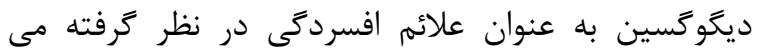

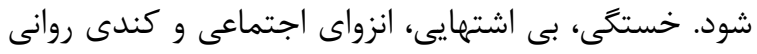

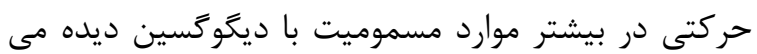

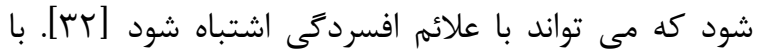
وجود اينكه درمانهاى دارويى نارسايى قلب اغلب يك فاكتور مهرم تشديد كننده افسردگى در بيماران نارسايى قلب دابل

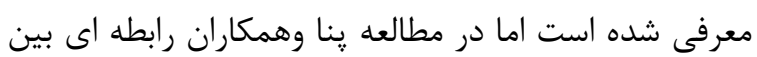
درمان هاى دارويى نارسايى قلبى با افسردگى مشاهده نشد

اين مسئله ضرورت انجام يزوهشهاى بيشتر به منظور

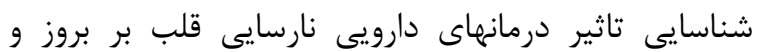

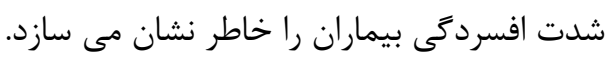

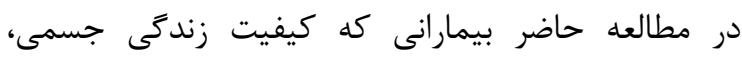
اقتصادى اجتماعى و روحى و روانى پايينترى داشتند از

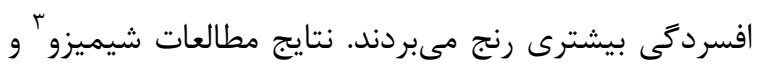

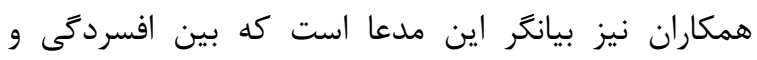
تمامى ابعاد كيفيت زندگى رابطه معكوس وجود دارد [19].

1 - Cardoso

2 - Song

3- Shimizu 
3. Redwine LSMills PJ, Hong S, Rutledge T, Reis V Maisel A,Irwin MR, Cardiac-related hospitalization and/or death associated with immune dysregulation and symptoms of depression in heart failure patients ,Psychosomatic Medicine 2007;69:23-9 .

4. Dekker RL,Peden AR, Lennie TA,Schooler MP, Moser DK, Living with depressive symptoms: patients with heart failure, Am J Crit Care 2009; 18(4): 310-18.

5. Pena FM, Modenesi Rde F, Piraciaba MC, Marins RM, Souza LB, Barcelos AF, Soares Jda $S$, Prevalence and variables predictive of depressive symptoms in patients hospitalized for heart failure, Cardiol J 2011; 18(1):18-25.

6. Cardoso G, Trancas B, Luengo A, Reis D, Heart failure and depression: an association with clinical importance, Rev Port Cardiol 2008; 27(1):91-109.

7. Pena FM, Silva Soares JD Costa Paiva BT, Piraciaba MC, Marins RM, Barcellos AF Muniz de Souza LB. Sociodemographic factors and depressive symptoms in hospitalized ,patients with heart failure, Exp Clin Cardiol 2010; 15(2): 29-32.

8. Vaccarino V, Kasl SV, Abramson J, Krumholz HM, Depressive symptoms and risk of functional decline and death in patients with heart failure, J Am Coll Cardiol 2001; 38:199205.

9. Koenig HG, Depression in elderly patients with congestive heart failure, Gen Hosp Psychiatry, 1998; 20:29-43.

10.Koenig HG, George LK,Depression and physical disability outcomes in depressed medically ill hospitalized older adults, Am J Geriatr Psychiatry1998; 6:230-47.

11.Rohyans LM, Pressler SJ, Depressive symptoms and heart failure: examining the sociodemographic Variables, Clin Nurse Spec 2009; 23(3): 138-44.

12. Faller H ,Stefan Störk S, Schowalter M,Steinbüchel T, Wollner V, Ertl G,Angermann $\mathrm{CE}$, Depression and survival in chronic heart failure: Does gender play a role? Eur J Heart Fail 2007 ; 9 (10): 1018-23.

13.Sherwood A, Blumenthal JA, Trivedi R, Johnson KS, OConnor CM, Adams KF Jr, Dupree CS, Waugh RA, Bensimhon DR, Gaulden L, Christenson RH, Koch GG, Hinderliter AL ,Relationship of depression to death or hospitalization in patients with heart failure, Arch Intern Med 2007; 167(4):367-73.
14.Zeighami Mohammadi Sh, Shahparian M, Fahidi F, Fallah E, Sexual dysfunction in men with systolic heart failure and associated factors ,Iranian Journal of Critical Care Nursing 2012; 5 (1) :35-42[Persian].

15.Guallar-Castillon P, Magarinos-Losada MM, Montoto-Otero C, Tabuenca AI, RodriguezPascual C, Olcoz-Chiva M, Conde-Herrera M, Carreno C, Conthe P, Martinez-Morentin E, Banegas JR, Rodriguez-Artalejo F, Prevalence of depression and associated medical and psychosocial factors in elderly hospitalized patients with heart failure in Spain ,Esp Cardiol 2006; 59(8):770-8.

16.Pintor L, Heart failure and depression, an often neglected combination, Rev Esp Cardiol 2006; 59(8):761-5.

17.Joynt KE, Whellan DJ, OConnor CM, Why is depression bad for the failing heart? A review of the mechanistic relationship between depression and heart failure, J Card Fail 2004; 10:258-71.

18.Chung ML, Lennie TA, Dekker RL, Wu JR, Moser DK, Depressive symptoms and poor social support have a synergistic effect on event-free survival in patients with heart failure, Heart Lung 2011; 29.

19.Shimizu Y, Yamada S, Miyake F, Izumi T, The effects of depression on the course of functional limitations in patients with chronic heart failure, J Card Fail 2011; 17(6):503-10.

20.Luber MP, Meyers BS, Williams-Russo PG, Hollenberg JP,DiDomenico TN, Charlson ME, Depression and service utilization in elderly primary care patients, Am Geriatr Psychiatry 2001;9:169-76.

21. Testa G, Cacciatore F, Galizia G, DellaMorte D, Mazzella F, Gargiulo G, Langellotto A, Raucci C, Ferrara N, Rengo F, Abete P, Depressive symptoms predict mortality in elderly subjects with chronic heart failure, Eur J Clin Invest 2011; 25.

22.Gottlieb SS, Khatta M, Friedmann E, Einbinder L, Katzen S, Baker B, Marshall J, Minshall S, Robinson S, Fisher ML, Potenza M, Sigler B, Baldwin C, Thomas SA, The influence of age, gender, and race on the prevalence of depression in heart failure patients, J Am Coll Cardiol 2004;43(9):1542-1549.

23.Macabasco-O'Connell A, Crawford $\mathrm{MH}$, Stotts N, Stewart A, Froelicher ES, Gender and racial differences in psychosocial factors of lowincome patients with heart failure, Heart Lung 2010;39(1):2-11. 
24.Sajadi M,Akbari A,Kianmehr M,Ataroudi A,The relationship between self-care and depression in patients undergoing hemodialysis, Ofogh-E-Danesh 2008; 14(1):13-17 [Persian].

25.Clark CM, Mahoney JS, Clark DJ, Eriksen LR, Screening for depression in Hepatitis C population: the reliability and validity of the center for epidemiologic studies depression scale (CES-D), Journal of Advances in Nursing 2002; 40(3):361-9.

26. Abbasi A,Nasiri $\mathrm{H}$,Specific instrument for assessment quality of life of chronic heart failure patients ,Journal of Gorgan Bouyeh Faculty Nursing and Midwifery 2006;3(2):41-5 [Persian].

27.Holzapfel N, Zugck C, Muller-Tasch T, Lowe B, Wild B, Schellberg D, Nelles M, Remppis A, Katus H, Herzog W, Junger J,Routine , screening for depression and quality of life in outpatients with congestive heart failure, Psychosomatics 2007; 48:112-6.

28.Koenig HG, Depression outcome in patients with congestive heart failure, Arch Intern Med 2006;166:991-6.

29.Zeighami Mohammadi SH ,Asgharzadeh Haghighi S, Falah N, The prevalence of anemia in elderly with systolic heart failure hospitalized in Alborz social security hospital of Karaj 2009,Iranian Journal Research Center on Aging (Salmand) 2010;16(2):25-34 [Persian].

30.Beghe C, Wilson A, Ershler WB, Prevalence and outcomes of anemia in geriatrics: a systematic review of the literature,Am J Med 2004; 116 (7):3-10.

31.Geiser F, Hahn C, Conrad R, Liedtke R, Sauerbruch T, Schmidt-Wolf I, Glasmacher A, Interaction of psychological factors and the effect of epoetin-alfa treatment in cancer patients on hemoglobin and fatigue, Support Care Cancer 2007; 15(3):273-8.

32.Song YH, Terao T, Shiraishi Y, Nakamura J, Digitalis intoxication misdiagnosed as depression-revisited, Psychosomatics 2001; 42(4):369-70. 
Original Article

\title{
Depression in male patients with systolic heart failure and related factors
}

\author{
Zeighami Mohamadi Sh*1, Shahparian $M^{2}$, Fahidy $F^{3}$, Fallah $E^{3}$
}

\footnotetext{
${ }^{1}$ Instructor of Nursing, School of Nursing and Midwifery, Islamic Azad University of Karaj, Iran

${ }^{2}$ Cardiologist, social security Alborz hospital,Karaj,Iran

${ }^{3}$ Nursing graduate, social security Shahriar hospital, Shahriar, Iran
}

*Corresponding Author:
School of Nursing and
Midwifery, Islamic Azad
University of Karaj, Iran
Email: zeighami@kiau.ac.ir

Revised: 2012 Jan 5

Accepted: 2012 Aug 15

Submitted: 2011 Jul 2

\begin{abstract}
Background \& objective: Depression associate with increase severity of illness, length of hospitalization and mortality in heart failure patient's. The aim of this study was to investigate the frequency and related factors of depression in male systolic heart failure patients.
\end{abstract}

Materials \& Methods: This is a cross sectional study that was conducted on 100 male patients with systolic heart failure in Alborz of Karaj and Shahriar Social Security Hospitals in 2010. Sampling method in this study was Convenience sampling. Data collected by demographic data form, MLHFQ (Minnesota Living with Heart Failure Questionnaire), (CES-D) Center for Epidemiologic Studies Depression Scale. Data was analyzed by SPSS software version 18 and using descriptive statistics, t-test, ANOVA and coefficient Pearson correlation.

Results: The findings indicated that mean score of depression was $20.3 \pm 12.47 \%$ had severe and $16 \%$ had mild to moderate depression. Depression significant associated with age $(p=0.002)$, education $(p<0.001), \quad$ economic $\quad$ status $(p=0.002)$, smoking $(p=0.034)$, hemoglobin level $(p=0.004)$, left ventricular ejection fraction $(p=0.012)$, use of digoxin $(p=0.019)$, angiotensin receptor blocker $(A R B)(p=0.005)$, aldacton $(p=0.005)$ and quality of life $(p<0.001)$.

Conclusion: Depression was common among men with systolic heart failure and had negative impact on quality of life. Nurses by screening and assessment symptoms of depression and refer patients for counseling and treatment can help to improve quality of life in heart failure patient.

Keywords: Heart failure, Depression, Quality of life 
